\title{
Recent Greenland Accumulation Estimated from Regional Climate Model Simulations and Ice Core Analysis*
}

\author{
K. DethlofF \\ Alfred Wegener Institute for Polar and Marine Research, Potsdam, Germany \\ M. SCHWAGER \\ Alfred Wegener Institute for Polar and Marine Research, Bremerhaven, Germany \\ J. H. Christensen AND S. KiILShOLM \\ Danish Meteorological Institute, Copenhagen, Denmark \\ A. RINKE AND W. DoRn \\ Alfred Wegener Institute for Polar and Marine Research, Potsdam, Germany \\ F. Jung-Rothenhäusler, H. Fischer, S. Kipfstuhl, And H. Miller \\ Alfred Wegener Institute for Polar and Marine Research, Bremerhaven, Germany
}

(Manuscript received 2 February 2001, in final form 7 March 2002)

\begin{abstract}
The accumulation defined as "precipitation minus evaporation" over Greenland has been simulated with the high-resolution limited-area regional climate model HIRHAM4 applied over an Arctic integration domain. This simulation is compared with a revised estimate of annual accumulation rate distribution over Greenland taking into account information from a new set of ice core analyses, based on surface sample collections from the North Greenland Traverse. The region with accumulation rates below $150 \mathrm{~mm} \mathrm{yr}^{-1}$ in central-northwest Greenland is much larger than previously assumed and extends about $500 \mathrm{~km}$ farther to the south. It is demonstrated that good agreement between modeled and observed regional precipitation and accumulation patterns exists, particularly concerning the location and the values of very low accumulation in the middle of Greenland. The accumulation rates in the northern part of Greenland are reduced in comparison to previous estimates. These minima are connected with a prevailing blocking high over the Greenland ice sheet and katabatic wind systems preventing humidity transports to central Greenland. The model reasonably represents the synoptic situations that lead to precipitation. Maxima of precipitation and accumulation occur at the southwestern and southeastern coasts of Greenland and are connected with cyclonic activity and the main storm tracks around Greenland. The central region of the Greenland ice sheet acts as a blocking barrier on moving weather systems and prohibits cyclones moving from west to east across this region and, thus prevents moisture transports.
\end{abstract}

\section{Introduction}

Climate varies on all timescales as a result of external forcings, like changes in solar radiation, aerosol loading, and atmospheric trace gases variations, as well as owing to internal fluctuations connected with atmospheric in-

* Alfred Wegener Institute for Polar and Marine Research Contribution Number 1720.

Corresponding author address: Dr. K. Dethloff, Alfred Wegener Institute for Polar and Marine Research, Telegrafenberg A43, Potsdam D-14473, Germany.

E-mail: dethloff@awi-potsdam.de stabilities and atmosphere-ocean interaction feedback processes as discussed for example in Palmer (1993) and Hansen et al. (1997). To understand the causes of recent climate changes and to distinguish between anthropogenic and natural climate variations, the reasons for climate changes in the past need to be investigated. The study of ice cores from the large ice sheets of Greenland is a powerful means to get information about the climate of the past. Time series of observational data from Greenland are available only for relatively short periods covering mainly the later part of the last century, so it is hard to analyze natural climate fluctuations on timescales beyond decades. The causes of twentieth- 
century climate variations are especially difficult to resolve because the period of instrumental records coincides with the time during which the atmosphere has been increasingly contaminated by human activities and anthropogenic influence such as greenhouse gases and aerosols.

Therefore, a detailed knowledge and quantitative reconstruction of past natural temperature and precipitation changes is crucial, in order for identifying the main climate-controlling factors. The scarcity of reliable long-term instrumental records calls for the use of sensitive proxy data. Isotopic records from the Greenland ice cores provide high-resolution temporal information on temperature and precipitation conditions during the formation of snow. Based on such information Fisher et al. (1996) compared oxygen-18 records for the polar sites in Canada and Greenland over the last 3500 yr on a 50-yr-average basis and identified two main spatial modes using the method of empirical orthogonal functions. Fischer et al. (1998b) successfully determined a distinct climate cooling during the Little Ice Age recorded in the northern Greenland ice cores. In order to understand the underlying mechanisms it is necessary to investigate the factors controlling the geopotential, temperature, and precipitation patterns over Greenland that determine the accumulation rates. Kapsner et al. (1995) compared accumulation rates and temperatures derived from the oxygen isotope composition of ice in the deep core obtained by the Greenland Ice Sheet Project. They find that atmospheric circulation and change in the storm tracks seems to have the primary control of snow accumulation in central Greenland.

Direct observations of Greenland precipitation are limited and the measurements of the mostly solid precipitation are strongly influenced by wind effects and mainly confined to complicated orographically influenced coastal stations. The information recorded in the ice is strongly affected by precipitation processes and the reliability of ice core interpretation depends highly on a clear understanding of the atmospheric processes that lead to the ice core accumulation.

Direct measurements of precipitation over Greenland are difficult. In the coastal regions precipitation measurements are available, but they are contaminated as a result of the strong wind influence and the snow drift, which can be quite large. Chen et al. (1997) suggested that precipitation must be determined indirectly by a dynamical approach using analyzed wind, geopotential height, and moisture fields. The annual precipitation over Greenland was evaluated by Bromwich et al. (1993) on the basis of a statistical model that captured the main features but underestimated the high precipitation at the west coast of Greenland. Dahl-Jensen et al. (1993) reconstructed accumulation rates of $210-230 \mathrm{~mm} \mathrm{yr}^{-1}$ for the ice sheet region of central Greenland on the basis of annual layer studies. Cullather et al. (2000) evaluated the atmospheric moisture budget over the Arctic Basin on the basis of the European Centre for Medium-Range
Weather Forecasts (ECMWF) Re-Analysis (ERA) and the National Centers for Environmental Prediction-National Center for Atmospheric Research (NCEP-NCAR) reanalysis data. They showed that significant differences exist between the different reanalysis datasets. Therefore, additional efforts are required to describe and understand the hydrological cycle over the Arctic Basin.

An alternative quantification of precipitation and accumulation in the Arctic region is provided by numerical models of the atmosphere, as discussed by Kattsov et al. (2000) and Christensen and Kuhry (2000). Most important mechanisms relating to a realistic simulation of present-day climate and climate changes require high spatial resolution. Extreme values of cyclone low pressure, intense precipitation and strong winds are generally more realistically described in nested regional climate models driven by observation-based reanalysis fields, as pointed out by Giorgi and Mearns (1999). The effect of anthropogenic greenhouse warming on the hydrological balance depends crucially on the ability to calculate a realistic snowpack and its melting (Christensen et al. 1998).

However, it is difficult to evaluate the high-resolution model results because only sparse data are available for comparison purposes. The hydrological cycle on a regional scale is poorly represented with a present-day coarse-resolution general circulation model as well as in the reanalysis products. The modeling and representation of atmospheric and surface processes on the regional scale necessarily needs a high horizontal resolution, especially in mountain regions and in areas with complicated land-sea contrasts and the presence of sea ice, as pointed out by Rinke et al. (2000).

Dethloff et al. (1996) and Rinke et al. (1999) integrated the regional climate model of the Arctic HIRHAM4 with a high horizontal resolution of around 50 $\mathrm{km}$ for the year 1990. This model was driven at the lateral and lower boundaries by time-dependent ERA data (Gibson et al. 1997). They showed that this model is able to reproduce the Arctic temperature and dynamical structures with reasonable accuracy. The strategy, underlying this technique, is that ECMWF analyses can provide the response of the global circulation to largescale forcings, and the nested limited-area model can account for the effects of the mesoscale forcing as a result of better resolved orography, nonlinear energy transfer, and hydrodynamic instability processes.

The topography of the Greenland ice sheet is very steep and the complicated mountains and orographic features around the margins, controlling most of the coastal precipitation, start to become resolved with a horizontal resolution of $50 \mathrm{~km}$, although even this scale is not small enough to enable a proper representation of all relevant orographic features. Compared with the ECMWF modeling system, the temperature and precipitation fields can be simulated substantially more accurately by using the state-of-the-art HIRHAM4 model, which properly accounts for the considerable ECMWF 
orography errors of typically several hundred meters near the ice sheet margins. This is crucial in modeling precipitation accumulation in that region of Greenland. Furthermore, the improved orography in a regional model has an influence on the cloud cover and the wind fields, which are important in getting a realistic surfacemass balance also over the interior parts. There are strong indications given for example by Christensen et al. (1998) that a more realistic simulation of precipitation can only be achieved by increasing model resolution. Christensen et al. (2001) pointed out that the water cycle to a very large degree depends on local and regional processes. Observational estimates of the hydrological cycle in the Arctic are extremely scarce and additional efforts are required to improve these data. Because regional climate models can capture the finescale structure of climate patterns, an important issue in evaluating these patterns is the lack of adequately dense observational data. This problem is profound in the Arctic region by the essential absence of any observational data for its central part and over the interior of Greenland. Given that the model simulates the climate realistically at a few spots with good observations, the model offers an opportunity to supplement the observations in data-sparse regions. High-resolution climate simulations over the Arctic might be an extremely fruitful tool in providing high-resolution fields of the hydrological variables for the determination of the surface energy budget (Lynch et al. 1999) and the Arctic freshwater budget (Kattsov et al. 2000; Christensen and Kuhry 2000).

In this paper we present the simulation results of precipitation and evaporation from a total of four years, the most comprehensive material available to us for the present analysis. We utilize 1990 data from the experiment described in Rinke et al. (1999) supplemented with data from a new HIRHAM4 experiment covering the years 1981-83. The latter period was chosen in order to depict a relatively short and continuous period with large interannual differences in Arctic sea ice extent. As will be documented later on (see Table 1), this period also encompasses more or less the entire range in annual precipitation readings for the network of meteorological rain gauge stations around Greenland. We compare these regional climate simulations with a revised map of precipitation using Greenland ice core analyses.

The paper is organized as follows. In section 2 we give information about the model HIRHAM4 and a description of the accumulation estimates based on new ice core analyses in the northern part of the Greenland ice sheet. Section 3 describes the simulated accumulation fields and compares these with the ice core data. Finally, section 4 summarizes and concludes the results.

\section{Model and observational data}

\section{a. Regional climate model HIRHAM4}

The dynamical regional climate model HIRHAM4 has been described in Christensen et al. (1996). The dynamical part of the model is based on the hydrostatic limited-area model (HIRLAM), documented by Machenhauer (1988) and Källén (1996). Prognostic equations exist for the horizontal wind components, temperature, specific humidity, liquid water content, and surface pressure. HIRHAM4 uses the physical parameterization package of the general circulation model ECHAM4, developed by Roeckner et al. (1996). These parameterizations include radiation, land surface processes, sea surface sea ice processes, planetary boundary layer, gravity wave drag, cumulus convection, and stratiform clouds. An advanced parameterization for precipitation processes is adopted. Convection is described in the Tiedtke (1989) mass-flux formulation with modifications to the formulation of deep convection. Liquid water in stratified clouds is a prognostic variable and is treated according to Sundqvist (1988). Land surface parameterizations use five prognostic temperature layers and one bucket moisture layer. In the presence of a snowpack over land with a depth exceeding 9-m water equivalent, the surface in the grid point is considered to be covered with ice recognized as a glacier point and soil temperature equations are solved with the characteristics of ice.

The integration domain covers the whole Arctic north of about $65^{\circ} \mathrm{N}$ with 110 by 100 grid points and a horizontal resolution of $0.5^{\circ}$ by $0.5^{\circ}$. The vertical discretization consists of 19 irregularly spaced levels in hybrid sigma-p coordinates from the surface up to $10 \mathrm{hPa}$ with five vertical layers in the planetary boundary layer. The model time step was 300 s. At the lateral and lower boundaries, HIRHAM4 was forced by the ERA data. The lateral forcing includes all prognostic variables except the liquid cloud water content. The information from the lateral boundaries was transferred to the model interior by a boundary relaxation in a 10 gridpoint-wide boundary zone with boundary data updated 4 times day $^{-1}$. At the lower boundary, ECMWF analyzed sea surface temperature and sea ice fraction has been used.

Results of model simulations in the Arctic, the validation against ECMWF analyses and station data, and intercomparison with the regional model ARCSyM over the Arctic were described by Dethloff et al. (1996), Rinke et al. (1997, 1999, 2000), and Kattsov et al. (2000). The sensitivity of the Arctic atmospheric simulations to initial and boundary conditions was investigated in Rinke and Dethloff (2000).

\section{b. North Greenland Traverse}

Validation data have been derived from Ohmura and Reeh (1991) and new accumulation data from the North Greenland Traverse (NGT) of the Alfred Wegener Institute (AWI). The traverse was carried out between 1993 and 1995 and designed to provide data on the regional and temporal variation of glaciometeorological and glaciochemical parameters in northern Greenland, 


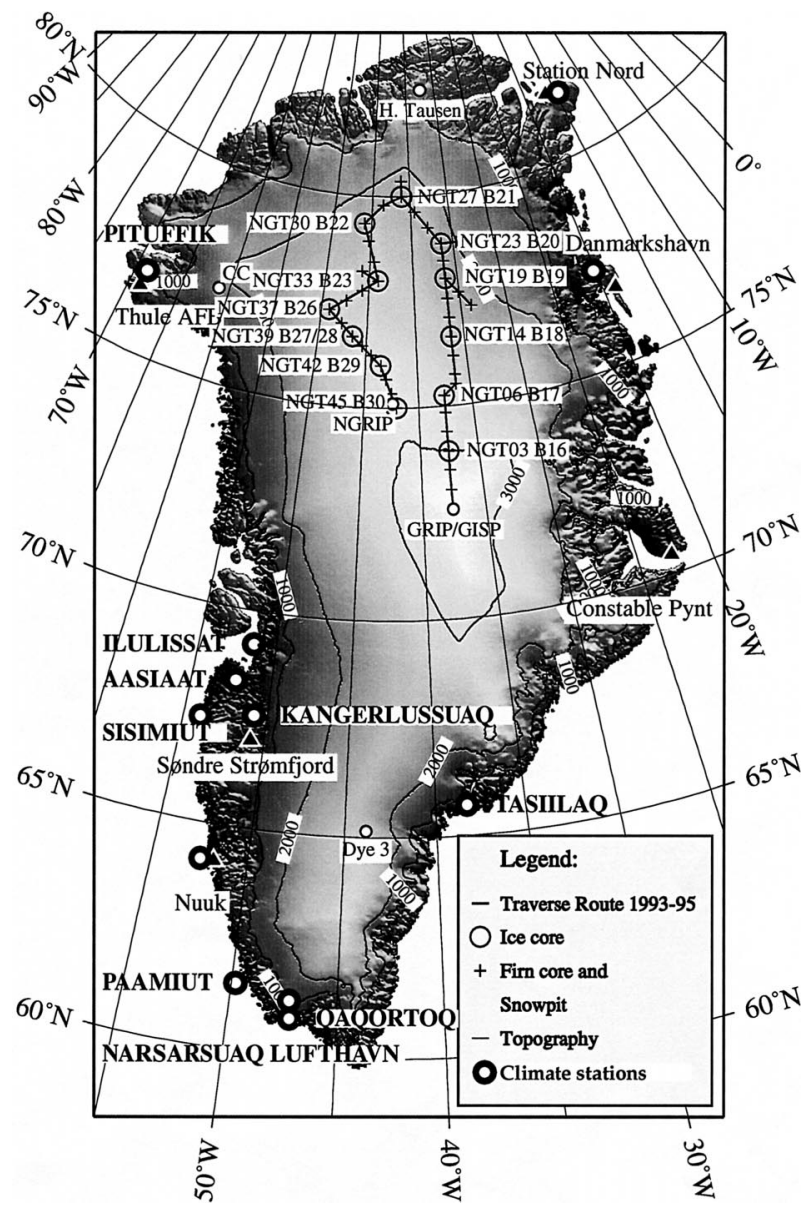

FIG. 1. The route of the NGT of the AWI with the locations of ice and firn cores and the drilling sites. The topography interval is 1000 $\mathrm{m}$. Locations of coastal rain gauge stations used in Table 1 are also shown.

one of the least studied areas of the Northern Hemisphere.

Figure 1 shows the traverse route as well as the positions of the individual analyzed ice and firn cores with the position of the drilling sites, the topography of Greenland described in Jung-Rothenhäusler et al. (2000, manuscript submitted to J. Glaciol., hereafter J-R) and the geographical position of selected climate stations around Greenland. These data allow the determination of accumulation rates for the central areas of northern Greenland. For the parts of the ice sheet and coastal regions not covered by the traverse investigations, we rely on the results of Ohmura and Reeh (1991). This basic dataset was recently improved by an objective interpolation procedure by Calanca et al. (2000). Their data, based on 27 regular meteorological stations along the coast and 22 short-term stations on the ice sheet, are extracted from various sources. The total annual accumulation was inferred using data from pit and core studies in the interior of the ice sheet. The results of objective interpolation in Calanca et al. (2000) are well in line with the subjective maps of Ohmura and Reeh (1991).

The rawinsonde network is the only other source of observational data for the atmospheric hydrological cycle over the North Polar basin. As shown by Cullather et al. (2000) there are strong differences in the precipitation and evaporation estimates from ERA and NCEPNCAR reanalysis datasets. Therefore, we compare here regional climate model simulated values of precipitation and evaporation with corresponding values from ice core parameter estimates over Greenland, an area without other observational estimates of precipitation and evaporation rates. The model is driven at the lateral boundaries by ERA (Gibson et al. 1997). Due to this real weather forcing the model is able to represent the main precipitation events observed over Greenland during the AWI traverse.

In the model simulations runoff is ignored since at least over central Greenland this term is very small, where temperatures are generally below the freezing point. Snow drift, which transports snow from one place to another, can be neglected, because it only redistributes the precipitated snow but does not mean any net mass gain or loss. At the coastal zones and the ice sheet edges snow drift and runoff can be important on smaller scales and for investigations of shorter time periods as considered in this paper.

The determination of mean annual accumulation rates from ice cores requires an accurate dating of these ice cores. In order to reduce the uncertainty in dating, a multiparameter approach for the analyses of firn and ice cores has been employed (Fischer et al. 1998a,b). Along the NGT route more than 40 firn cores (each 10-15 m long) and 12 shallow ice cores (each 100$175 \mathrm{~m}$ long) were drilled using a $100-\mathrm{mm}$ electromechanical drill. Core density was determined directly in the field by measuring and weighting each piece of core. Furthermore, electrical conductivity (dielectrical profiling; Wilhelms et al. 1998) was measured before bagging to obtain a record of the major volcanic events and preliminary ages of the ice cores. Analyses of ammonium, calcium, and hydrogen peroxide were carried out by a continuous flow analysis (CFA) system (Sommer 1996; Bigler et al. 2001, manuscript submitted to Ann. Glaciol.). The continuous measurements of electrical conductivity, gamma attenuation density (Wilhelms 1996) and CFA provide annual layer signals to date the cores. Volcanic eruptions of Katmai (A.D. 1912), Tamora (A.D. 1816), Laki (A.D. 1783), and others provided time marker horizons. The accuracy of the dating is estimated to better than three years. From the ice cores, high-resolution gamma attenuation density with a resolution of $1 \mathrm{~mm}$ was used to determine the accumulation rate. For the ice cores the accumulation rate was derived using an interpolated density profile based on the density measured on core pieces at the drilling site. The NGT data allow us to determine the accumulation for the most central areas of northern 
Greenland over the last 500-1200 yr in annual resolution and to supplement the accumulation map of Ohmura and Reeh (1991) in this less investigated area. This latter accumulation map was reevaluated by Ohmura et al. (1999) with more recent information including the NGT data. In contrast, the (geographical information system) GIS-based approach to integrate new accumulation data into the accumulation map of Ohmura and Reeh (1991) presented in Jung-Rothenhäusler (1998) and J-R is used here. The GIS-based approach offers a higher flexibility in the treatment of new data and has the advantage to generate accumulation maps for varying time intervals and to test different interpolation algorithms. The existing accumulation map (Ohmura and Reeh 1991) was scanned and the isopleths were digitized after geocoding. These isopleths served as input data for a spatial interpolation. A minimum curvature spline algorithm (Smith and Wessel 1990) was found to be most suitable for the digital reproduction of the accumulation field of Ohmura and Reeh (1991). In the area with less than $200 \mathrm{~mm}$ (water equivalent) in northeast Greenland the isopleths of Ohmura and Reeh (1991) were removed and the accumulation data derived from the NGT cores over the period 1912-93 were included. This period was chosen because the Katmai volcanic eruption is the first volcanic horizon common to all analyzed NGT ice cores and the data used by Ohmura and Reeh had been acquired between 1913 and 1990. Interpolation of the NGT accumulation data into Ohmura and Reeh's map was again carried out with the minimum curvature algorithm by Smith and Wessel (1990).

\section{Results}

\section{a. Simulated precipitation and accumulation rates over Greenland}

Although, we will concentrate on the models ability to simulate the atmospheric input to the mass balance of the Greenland ice sheet, a brief introduction to the hydrological cycle for the entire Arctic model region is relevant. High precipitation amounts are found over the Atlantic Ocean associated with the storm track entering the Arctic via the Nordic Seas. At the southern coast of Greenland and along the western side of Scandinavia, strong precipitation maxima occur. Extremely low precipitation values are found over central Greenland and the western part of the Arctic Basin with the lowest precipitation values over the central and northern part of Greenland at the ice sheet with values never exceeding $100 \mathrm{~mm} \mathrm{yr}^{-1}$. The annual cycle of Arctic precipitation, based on observations and HIRHAM4 simulations, has been investigated in Kattsov et al. (2000). This indicates a precipitation peak of $1.2-1.3 \mathrm{~mm} \mathrm{day}^{-1}$ in late summer/early autumn while values of around 0.8 $\mathrm{mm}$ day $^{-1}$ are representative during winter. At the southern coast of Greenland the precipitation is mainly a result of large-scale humidity transports connected with transient weather systems, enhanced by substantial orographic lifting.

Modeled evaporation rates show the highest values over the ice-free and relatively warm ocean regions. Condensation occurs over central Greenland implying a mean subsidence over that area. Both are consistent with findings in the previous work of Gorchkov (1983) and in particular in the ERA by Cullather et al. (2000). The accumulation rates defined as the precipitation minus evaporation rate show positive values over the whole Arctic with the highest values in the coastal zone of southern Greenland, while in the Barents Sea negative accumulation rates occur indicating a dominance of evaporation processes in that area (not shown). Again this compares well with the ERA (i.e., Cullather et al. 2000).

Figure 2 shows the simulated mean annual accumulation rates described by the "precipitation minus evaporation" $(P-E)$ fields over Greenland averaged over the years 1981-83 and 1990. Over Greenland the lowest

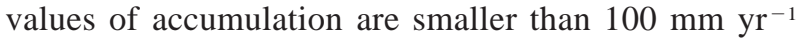
in all years. Since the evaporation in the central part of Greenland is small or even negative, indicating condensation, the accumulation field is determined mainly by the precipitation patterns there. It is noticed that all the areas with relatively high $P-E$ values, are associated with sloping terrain causing high precipitation values by orographic lifting.

Figure 3 shows the standard deviation of $P-E$ of the four modeled years. Pronounced variability from year to year occurs in the minima of the accumulation rates over central Greenland and the maxima at the southwestern part of Greenland. In the present case, the largest relative interannual variation occurs on the southwestern slopes of the ice sheet, while the very low accumulation rate areas in the interior northeast display very small interannual variations. Likewise the low values along the shores of the Nares Strait separating Greenland from Ellesmere Island are relatively robust. Whether these values are representative for this region is difficult to judge as the observation material is extremely sparse here. The results from Ohmura and Reeh (1991) and later updates in Calanca et al. (2000) and in the present paper, are all based on a few Canadian sites (one important one being the station Alert on the north coast) on the shore of Ellesmere Island. The very low simulated values do however compare reasonably with the recent update by Ohmura et al. (1999). The simulated interannual variability compares well with observational precipitation datasets for the same periods as evident in Table 1.

Table 1 lists quality-controlled observed annual mean precipitation for 12 stations maintained by the Danish Meteorological Institute in Greenland for the years 1981-83 and 1990, published by Cappelen et al. (2000). For most of the stations these figures are identical or very close to the absolute highest and lowest values 

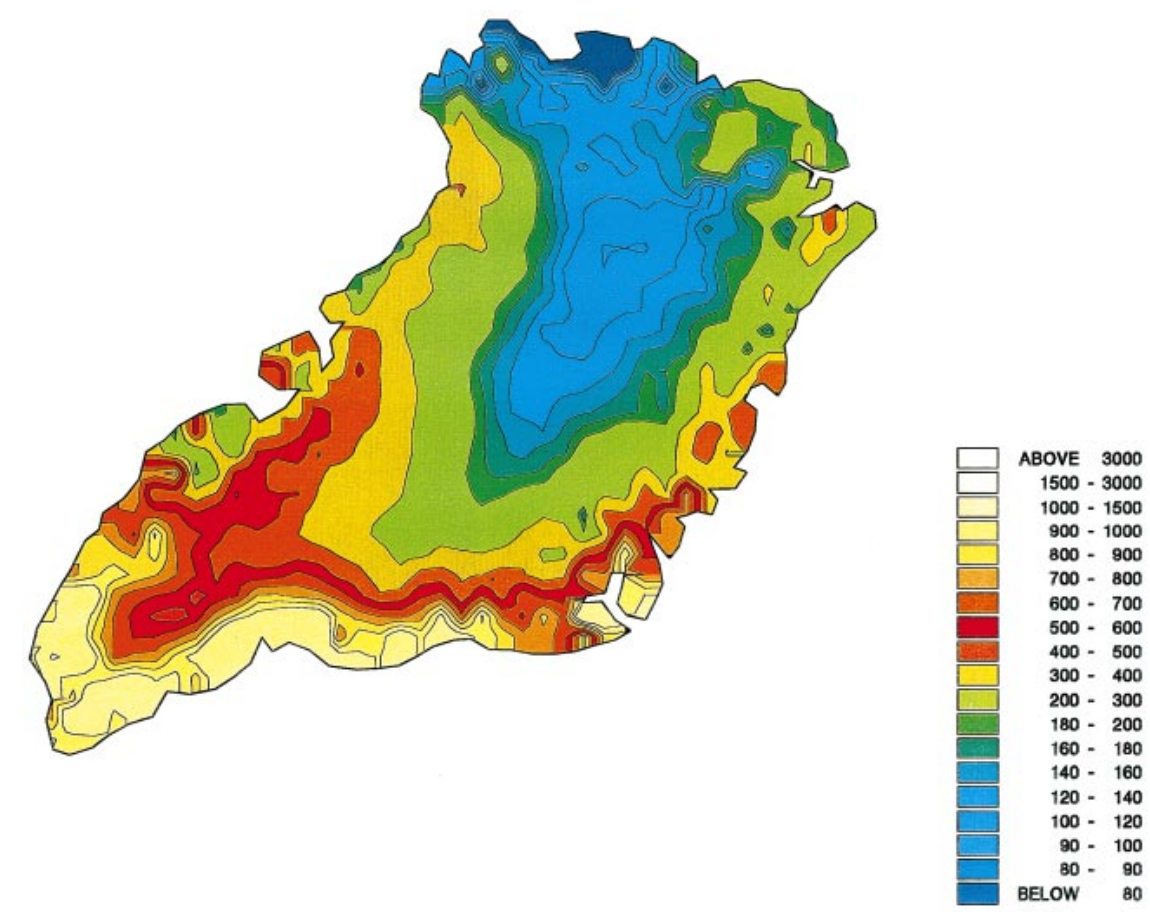

FIG. 2. Mean annual accumulated $P-E(\mathrm{~mm})$ over Greenland based on simulations with the HIRHAM4 model for the years 1981-83 and 1990.

observed within the last 40 years. Figure 1 shows the location of the stations. For comparison the corresponding highest and lowest values from the regional model simulations for the same four years are shown. The highest and lowest values at each station are shown in bold. When comparing these highest and lowest values, it is recognized that the simulated variability is quite representative for that observed close to almost all sites with observed data for all years. But it is noticed as well that with only 12 coastal stations such a statement is only indicative that the model is doing reasonably well in the coastal regions. The lowest values in the standard deviation occur over central Greenland. The highest values appear at the western and eastern coasts in agreement with the values in Table 1.

The HIRHAM4 simulations underestimate the precipitation in the years 1981-83 and overestimate the precipitation in the year 1990 in coastal areas. The spatial distribution is very similar to the observations. As Rogers et al. (1998) showed, the years 1982-84 described an unusually cold episode around Greenland and the Baffin Island connected with cold pools of water in the northern Atlantic as a result of interaction between the sea surface and air temperatures and the atmospheric circulation. The year 1990 was unusually warm in the Arctic with a very low sea ice concentration, as pointed out by Serreze et al. (1995) and Deser at al. (2000). These unusually warm conditions were part of a largerscale temperature anomaly pattern, linking the sea ice anomaly to accompanying minima in the Eurasian snow cover. Serreze et al. (1997) counted the number of cyclones for the years 1966-93 and showed that this number was much higher during 1990 compared to 198183. This is in agreement with the HIRHAM4 simulations showing more precipitation in years with stronger cyclonic activity and less precipitation in years with reduced cyclones.

The differences between the measurements and the simulations might thus be connected with deviation in the simulations of the dynamics compared with the real atmosphere and especially in the lower boundary conditions concerning sea surface temperatures and sea ice distribution. This means that low pressure systems and connected precipitation events might be misrepresented by the model at different times or locations. The model could further under- or overestimate precipitation for given precipitation events and there also exist uncertainties in the measurements in orographic complex areas. Additionally, the currently used horizontal resolution of $50 \mathrm{~km}$ smoothes orographic features of Greenland to a certain degree.

In comparing our simulated values from 4 years with the 15 years of ERA, it is noted that there is a good agreement concerning the areal distribution between minima and maxima in $P-E$ (cf. Fig. 2 in Cullather et al. 2000). With the caveat in mind that we compare an uneven number of years, we notice a tendency of HIRHAM4 to enlarge the extremes. More precisely, the areas with low accumulation rates identified in HIRHAM4 simulations tend to be lower than in the ERA data, and 

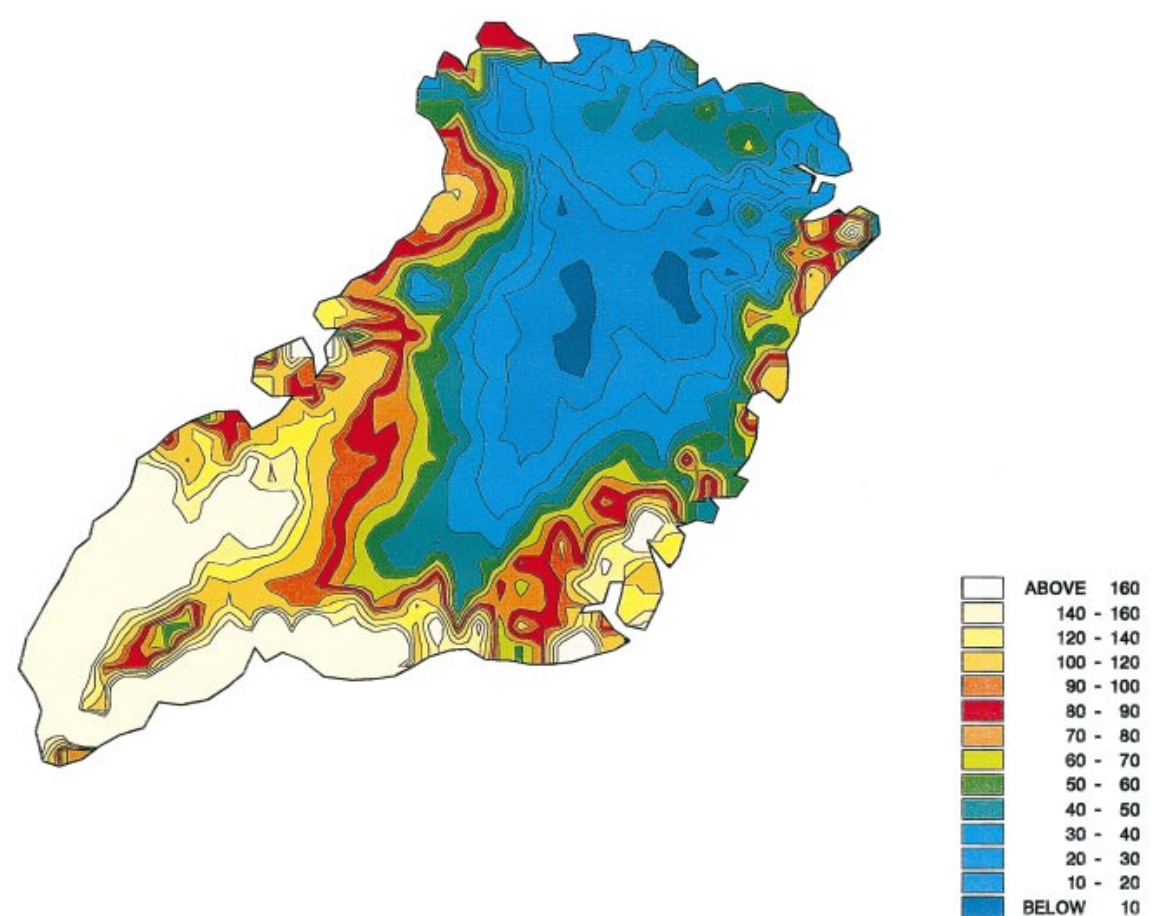

Fig. 3. Standard deviation of annual accumulated $P-E$ for the years $1981-83$ and 1990 .

the more intensively accumulating coastal zones in the south exhibit a much higher rate in HIRHAM4 than in ERA. Most of this can be explained by the finer horizontal resolution in HIRHAM4 and appears to be more realistic on the regional to local scale (see also Christensen et al. 1998). Rinke et al. (2000) studied the January and June circulation of the year 1990 over the whole Arctic and showed that in the ERA data a high pressure system also develops over Greenland. Differences between the ERA data and the HIRHAM simulations exist in the position and the maximum values due to a misrepresentation of the steep ice sheet margin at Greenland in the ERA data, which tends to broaden and systematically overelevate the orography by several hundred meters.
The measured accumulation field for Greenland using the ice and firn cores from the AWI Traverse in Fig. 1 is presented in Fig. 4. In comparison with the results of Ohmura and Reeh (1991) the accumulation rates over the northern part of the ice sheet are smaller, although they are in better agreement with the recent update by Ohmura et al. (1999) and Calanca et al. (2000). The region with accumulation rates below $150 \mathrm{~mm} \mathrm{yr}^{-1}$ is much larger than previously assumed and extends about $500 \mathrm{~km}$ farther to the south. The new result concerns the enlarged size of the low-accumulation region in central northwest Greenland. For the area west of the the main ice divide, mean accumulation rates are about $20 \%$ higher than in the eastern part. The drop in accumulation is more pronounced just north of central Greenland. In

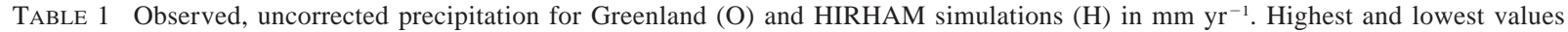
for each station are shown in bold.

\begin{tabular}{|c|c|c|c|c|c|c|c|c|c|}
\hline Station name & $\begin{array}{l}\text { Station } \\
\text { number }\end{array}$ & $1981(\mathrm{O})$ & $1981(\mathrm{H})$ & $1982(\mathrm{O})$ & $1982(\mathrm{H})$ & $1983(\mathrm{O})$ & $1983(\mathrm{H})$ & $1990(\mathrm{O})$ & $1990(\mathrm{H})$ \\
\hline Pituffik & 4202 & & 119 & & 96 & 133.8 & 74 & 46.4 & 192 \\
\hline Ilulissat & 4216 & 264.3 & 242 & & 187 & 304.5 & 260 & & 432 \\
\hline Aasiaat & 4220 & 311.7 & 200 & 230.9 & 155 & 303.8 & 224 & 361.7 & 416 \\
\hline Sismiut & 4230 & 525.8 & 240 & 339.3 & 194 & 536.1 & 256 & 358.1 & 344 \\
\hline Kangerlussuaq & 4231 & 122.4 & 219 & 145.6 & 158 & 225.3 & 317 & 152.6 & 412 \\
\hline Nuuk & 4250 & 770.0 & 446 & 488.1 & 377 & 1146.0 & 655 & 690.2 & 936 \\
\hline Paamiut & 4260 & 939.0 & 627 & 598.7 & 483 & 1453.5 & 791 & 934.0 & 1435 \\
\hline Narsarsuaq Lufthavn & 4270 & 599.7 & 622 & 456.7 & 538 & 1049.7 & 756 & 794.6 & 1140 \\
\hline Qaqortoq & 4272 & 655.0 & 791 & 756.9 & 660 & 1445.9 & 916 & 998.5 & 1652 \\
\hline Station Nord & 4310 & & 120 & & 129 & 168.7 & 118 & 321.5 & 800 \\
\hline Danmarkshavn & 4320 & & 219 & 160.3 & 274 & 172.8 & 285 & 308.9 & 612 \\
\hline Tasiilaq & 4360 & 823.4 & 649 & 790.1 & 730 & 972.2 & 762 & 906.3 & 1596 \\
\hline
\end{tabular}




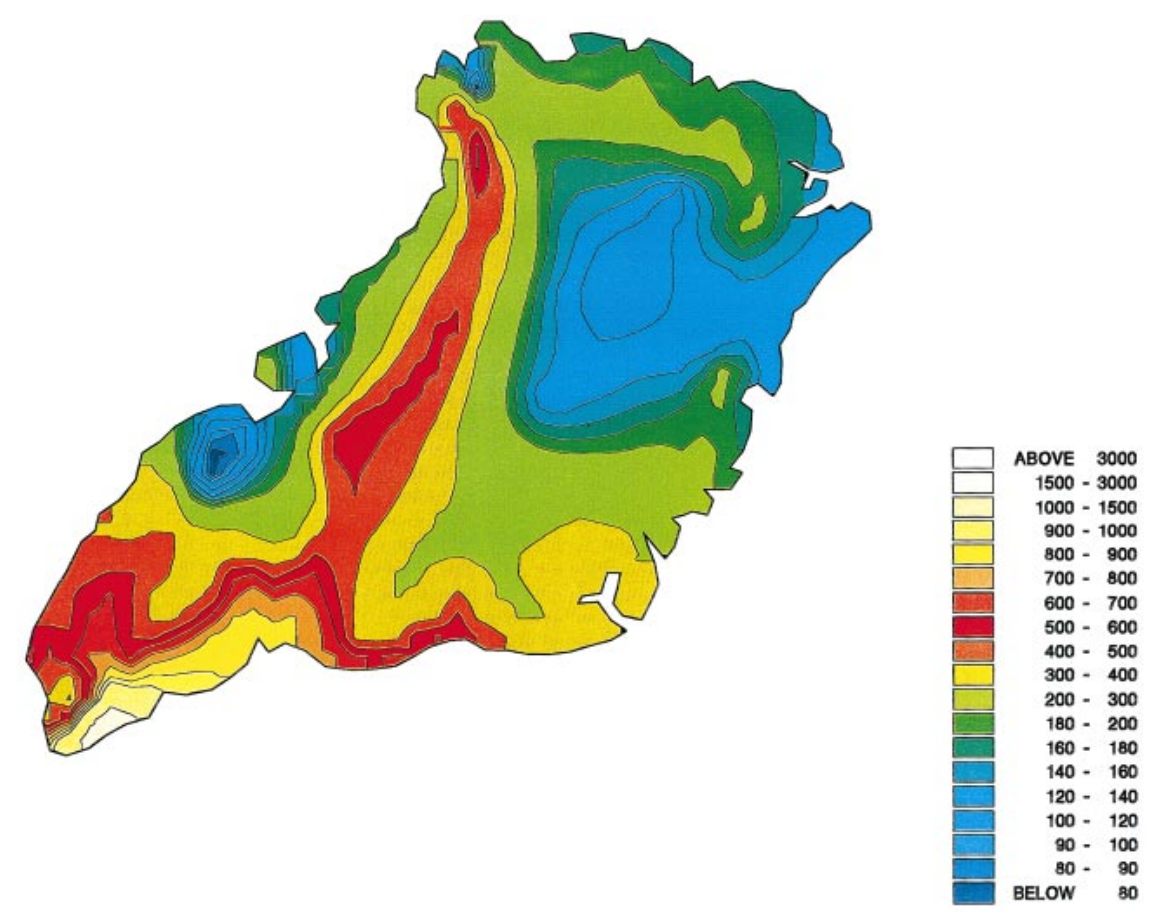

FIG. 4. Annual total accumulation (mm) over Greenland from the traverse route using ice cores, firn cores, and additional observations of Ohmura and Reeh (1991).

general the accumulation rates in the northern half of Greenland appear to be reduced in comparison to previous estimates.

Compared with the new ice core observations in Fig. 4, the simulations in Fig. 2 reproduce the observations in the overall structure and in particular the minimum values from 80 up to $100 \mathrm{~mm} \mathrm{yr}^{-1}$ over central Greenland. The modeled accumulation and precipitation minima compare well with the observations, although over central Greenland a shift in the accumulation patterns between different years can be detected. In the observations a belt of relatively high accumulation stretches from north to south at the western part of Greenland. This belt also occurs more weakly in the simulations, but it is not a stable feature as can be deduced from Fig. 2. The extreme northwest coast measured values are different from the simulations and probably connected with shifts in the climatic regimes over the last century.

At the southeastern and southwestern coasts of Greenland pronounced differences between the HIRHAM4 simulations and the observations occur. The simulated accumulation at the southwest and at the southeast coast of Greenland is higher than in the observations with better agreement in the accumulation and precipitation maxima at the southeast coast. This must be related to a well-known undercatchment at the rain gauges when the precipitation is solid (e.g., Sevruk 1986; Allerup et al. 1997, 2000; Christensen et al. 1998). Furthermore, point measurements of precipitation in complex topographical terrain are not likely to be representative for grid squares covering $50 \mathrm{~km}$ by $50 \mathrm{~km}$ (Christensen et al. 1998; Christensen and Kuhry 2000). These maxima of more than $1000 \mathrm{~mm} \mathrm{yr}^{-1}$ are connected with cyclonic activity as pointed out by Chen et al. (1997) with large interannual changes.

In many aspects the simulations are also grossly in agreement with the accumulation distribution of Genthon and Braun (1995), Chen et al. (1997), and in particular Bromwich et al. (1998), who also identified a pronounced minimum of $100 \mathrm{~mm} \mathrm{yr}^{-1}$ at the summit of Greenland in correspondence with the simulated accumulation minima shown in Fig. 2. In the two latter studies, statistical-dynamical approaches based on physical relations are used to downscale large-scale dynamical information to a resolution comparable to what we have adopted in this study. However, in neither of the studies are fully comprehensable parameterization of precipitation processes taken into account, while this is done in this study.

In the interior of Greenland at the top of the ice sheet, the accumulation is always low with $200 \mathrm{~mm} \mathrm{yr}^{-1}$. The simulated value compares well to the estimated change in surface elevation of $210-230 \mathrm{~mm} \mathrm{yr}^{-1}$ for the central region of Greenland by Dahl-Jensen et al. (1993). The current atmospheric circulation conditions, therefore suggest a Greenland ice sheet that, near the top, is close to a steady state with small accumulation rates. On the contrary, at the southeast coast the accumulation rate exceeds $2500 \mathrm{~mm} \mathrm{yr}^{-1}$, which may be important for minor coastal glaciers. 


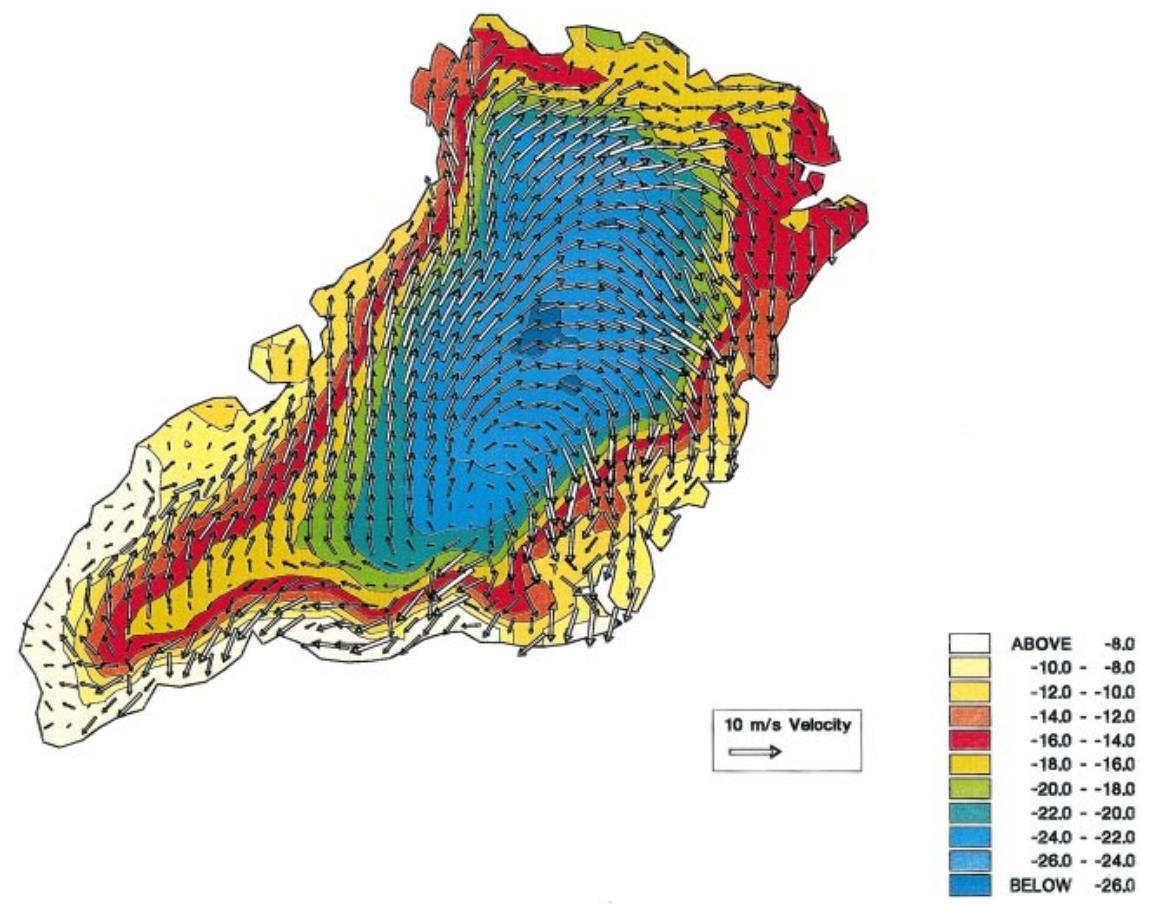

FIG. 5. Annually averaged wind vectors $\left(\mathrm{m} \mathrm{s}^{-1}\right)$ and temperature $\left({ }^{\circ} \mathrm{C}\right)$ at model level 19 corresponding to a height of $34 \mathrm{~m}$ above the ice sheet over Greenland based on model simulations with HIRHAM4 for the year 1990.

\section{b. Greenland wind and temperature}

The Greenland ice sheet has a large albedo and hence reflects the incoming shortwave radiation effectively. Over the central part of Greenland, the main part of the shortwave solar radiation is reflected and the solar radiation absorbed at the surface is as low as $20 \mathrm{~W} \mathrm{~m}^{-2}$ as estimated from the HIRHAM4 run for the year 1990. The simulated emitted longwave radiation from the ice surface is above $28 \mathrm{~W} \mathrm{~m}^{-2}$. This causes an effective cooling at the surface and a downward sensible and latent heat transfer from the atmosphere to the surface and leads to a descent of air over the interior of Greenland, which prevents or reduces cloud cover and contributes to the development of the Greenland surface high. The subsidence over the central region of Greenland contributes to the very low precipitation in this area.

Figure 5 shows the simulated annually averaged wind vectors at the lowest model level corresponding to a height of about $34 \mathrm{~m}$ above the ice sheet over Greenland together with the temperature at the same level. A high pressure area over Greenland drives katabatic winds from the interior plateau to the Arctic and Atlantic Ocean sides. This katabatic wind system extends up to heights of about $2300 \mathrm{~m}$ above the ice sheet, not shown here. The prevailing katabatic winds prevent humidity transports to the northern part of the Greenland ice sheet. As pointed out by Chen et al. (1997), the central region of Greenland has an important blocking effect on mov- ing cyclones. They analyzed two years 1987 and 1988 in which no cyclone moving from west to east across this region was identified. As shown by Bromwich et al. (1999) the annual precipitation pattern over the northern coastal, central-west, central-interior, and central-east regions of Greenland for an individual year is similar to that of the mean annual precipitation for the period 1985-95. This result is underlined by our own simulations showing moderate differences in the regional precipitation patterns over the above-mentioned regions of Greenland from year to year. The simulated annually averaged surface temperature distribution seems to be a reasonable representation for the mean temperatures in Greenland from May 1985 to April 1991 (e.g., Genthon and Braun 1995).

\section{c. Cyclonic activity at the Greenland perimeter}

The main $P-E$ pattern in Fig. 2 and the strong interannual variability in Fig. 3 at the southern coastal regions is completely determined by cyclonic activity. Chen et al. (1997) indicated four primary cyclone tracks around Greenland as a result of the thermal and dynamical effects of the topography of Greenland's ice sheet.

Figure 6 shows the number of cyclones computed with the algorithm of Serreze et al. (1993, 1997). This detection and tracking algorithm for the cyclones makes use of the 6-hourly sea level pressure fields to compute the spatial distribution of cyclones based on data of 13 


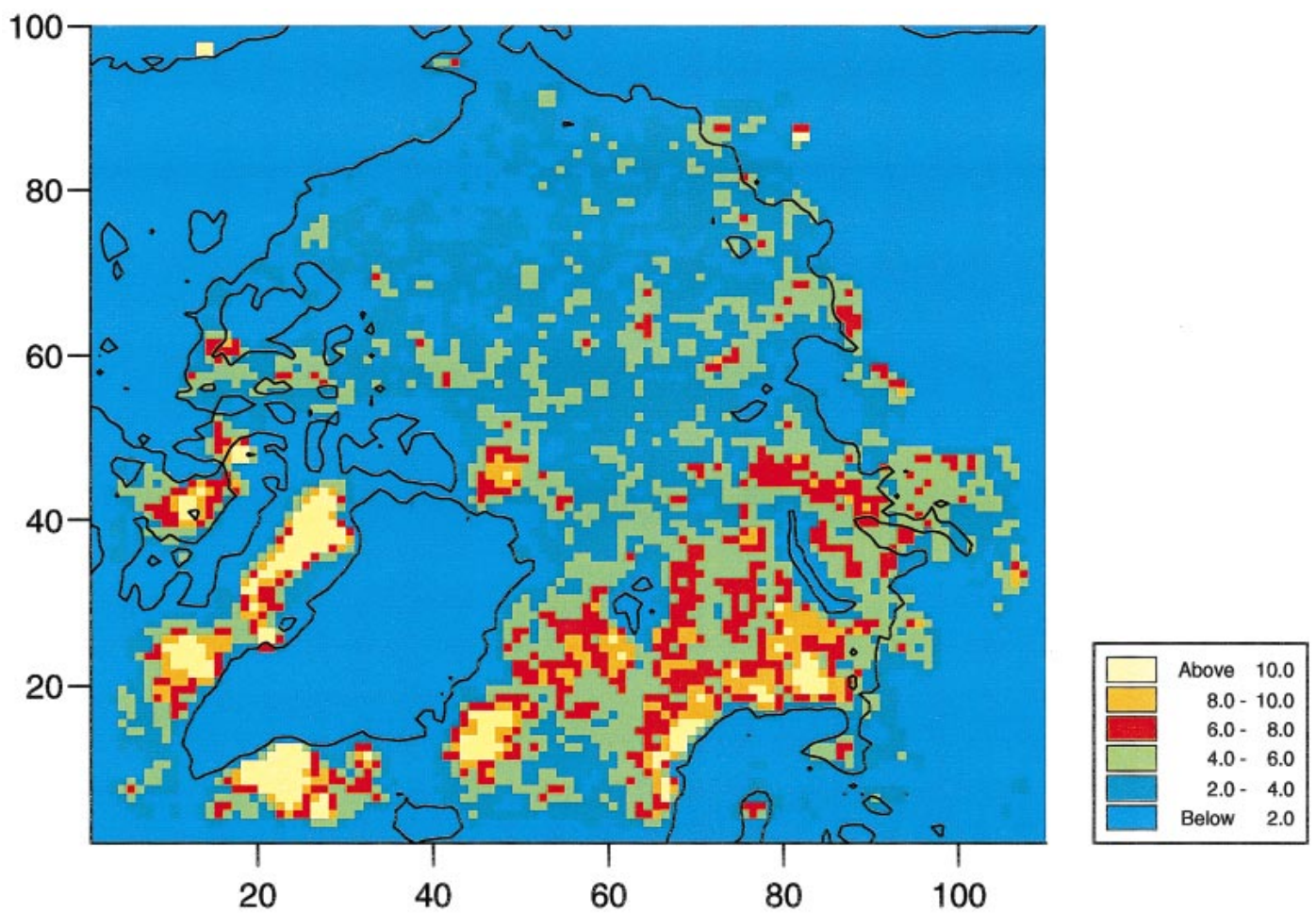

FIG. 6. Storm tracks (number of cyclones) around Greenland based on model simulations for $13 \mathrm{yr}$ with HIRHAM4 using the algorithm of Serreze et al. $(1993,1997)$.

years: 1961-64, 1968, 1978, 1982, 1988-91, 1993-94. One cyclonic track is related to circulations connected with the Icelandic low, very well reproduced by the HIRHAM4 simulations at the south coast of Greenland. A second track is a major storm track stretching from the south along the western coast of Greenland into the Baffin Bay. A third track represents a cyclone moving at the southernmost part of Greenland and tracking through the Denmark Strait. A fourth storm track is due to cyclones formed within the Baffin Bay itself, which sometimes cause precipitation over the north coastal region of Greenland. These main cyclone tracks can explain the mean precipitation patterns over Greenland throughout the year. The strong precipitation in the southern region of Greenland is a result of cyclonic activity connected with the described four storm tracks shown in Fig. 6 that are in agreement with those discussed in Serreze et al. (1993, 1997), Chen et al. (1997), and Bromwich et al. (1998).

\section{Conclusions}

Annual precipitation and evaporation for a total of four years has been simulated over Greenland with a high-resolution limited-area climate model of the Arctic and compared with a combination of new estimates of the annual accumulation distribution over north-central Greenland deduced from inland ice core parameters and material already in the literature. A good agreement in the regional precipitation patterns exists concerning the location and the values of very low accumulation and precipitation in the central northwest part of Greenland, but also for many regional features in the coastal areas, where information can be extracted from gauge measurements. The region with accumulation rates below $150 \mathrm{~mm} \mathrm{yr}^{-1}$ in central-northwest Greenland is much larger than previously assumed and extends about 500 $\mathrm{km}$ farther to the south. Contrary to this, the ERA and NCEP-NCAR data suggest much higher accumulation rates at the Greenland ice sheet and shows lower peak values in areas with high accumulation rates. The precipitation minimum is connected with a stationary high pressure area and katabatic wind systems, which effectively prevent humidity transports to the central part of Greenland. Maxima of accumulation and precipitation occur at the southwest and southeast coasts of Greenland connected with cyclonic activity in four main storm tracks. While the southeastern accumulation band is at least qualitatively reproduced by the simulations, there is a regional shift in the southwestern precipitation band between simulations and observations, connected with interannual storm track variability.

To a large extent this shift can be explained by the small number of simulation years we have in our sample. As demonstrated, the southern part (south of $65^{\circ}$ ) of Greenland is under the influence of very large interannual fluctuations in the amount of precipitation received. Furthermore, the years we have chosen for this 
particular work encompasses some of the most extreme dry and wet years observed over the last 40 years. This variability underlines the need for even longer simulation in order to reduce the uncertainties associated with accumulation estimates. Despite the intrinsic caveat in comparing four simulation years with an accumulation map, which has no specific dating, except from representing the twentieth century, we have shown that the HIRHAM4 model is doing a promising job in simulating those observed accumulation rates. The model seems to depict the dynamical forcings, which are responsible for the great variation in precipitation geographically as well as interannually. In particular we notice that the low accumulation rates in the interior at the top of the ice sheet of Greenland seems to be very realistically simulated, while it is more difficult to assess in a quantitative sense the accumulation rates in the coastal areas, where the local variations are large and observations very sparse. Four main cyclone tracks identified by Serreze et al. (1993) and Chen et al. (1997) have also been identified in the HIRHAM4 simulations. These determine the precipitation patterns in the coastal regions. There is a very strong connection between precipitation and cyclonic activity. This finding is in general agreement with the results of Kapsner et al. (1995) that atmospheric circulation and a change in the storm tracks seems to have the primary control of snow accumulation in central Greenland.

The state-of-the-art model HIRHAM4 represents the spatial variations of Greenland precipitation quite realistically since it is able to reasonably represent the synopotic situations that lead to precipitation. The $P-$ $E$ fields are not due to local effects but representative for a larger area. This underlines the value and importance of ice core data for representing at least regional climate features. The central region of Greenland acts as a barrier on moving weather systems and prohibits cyclones moving from west to east across this region and, thus, preventing transglacial moisture transports.

Acknowledgments. Financial support for this study was provided by the strategy fund project "Natural Climate Variations from 10,000 Years BP to the Present Day" (Klima in historischen Zeiten) of the Helmholtz Association of German Research Centres. The HIRLAM system was developed by the HIRLAM project group, a cooperative project of the national weather services in Denmark, Finland, Iceland, Ireland, Netherlands, Norway, Spain, and Sweden. We thank Ines Hebestadt and Barbara Weisheimer for computational support and Helga Henschel for improving our English.

\section{REFERENCES}

Allerup, P., H. Madsen, and F. Vejen, 1997: A comprehensive model for correcting point precipitation. Nordic Hydrol., 28, 1-20. ,-- , and -2000 : Correction of precipitation in Greenland. Proceedings of the Nordic Hydrological Conference, T. Nilsson, Ed., NHP Rep. 46, 225-232.
Bromwich, D. H., R. A. Keen, and J. F. Bolzan, 1993: Modeled variations of precipitation over the Greenland ice sheet. J. Climate, 6, 1253-1268.

_ R. I. Cullather, Q. S. Chen, and B. M. Csatho, 1998: Evaluation of recent precipitation studies for Greenland ice sheet. J. Geophys. Res., 103, 26 007-26024.

—_, Q. S. Chen, Y. Li, and R. I. Cullather, 1999: Precipitation over Greenland and its relation to the North Atlantic Oscillation. $J$. Geophys. Res., 104, 22 103-22 115.

Calanca, P., H. Gilgen, S. Ekholm, and A. Ohmura, 2000: Gridded temperature and accumulation distributions for Greenland for use in cryospheric models. Ann. Glaciol., 31, 118-120.

Cappelen, J., B. V. Jorgensen, E. V. Laursen, L. S. Stannius, and R. S. Thomsen, 2000: The observed climate of Greenland, 195899, with climatological standard normals, 1961-90. DMI Tech. Rep. 00-18, DMI, Copenhagen, Denmark, 149 pp.

Chen, Q. S., D. H. Bromwich, and L. Bai, 1997: Precipitation over Greenland retrieved by a dynamic method and its relation to cyclonic activity. J. Climate, 10, 839-870.

Christensen, J. H., and P. Kuhry, 2000: High resolution regional climate model validation and permafrost simulation for the EastEuropean Russian Arctic. J. Geophys. Res., 105, 29 647-29 658.

_- O. B. Christensen, P. Lopez, E. van Meijgaard, and M. Botzet, 1996: The HIRHAM4 regional atmospheric climate model. DMI Scientific Rep. 96-4, DMI, Copenhagen, Denmark, 51 pp.

Christensen, O. B., J. H. Christensen, B. Machenhauer, and M. Botzet, 1998: Very high-resolution regional climate simulations over Scandinavia-Present climate. J. Climate, 11, 3204-3229.

_- M. A. Gaertner, J. A. Prego, and J. Polcher, 2001: Internal variability of regional climate models. Climate Dyn., 17, 875887.

Cullather, R. I., D. H. Bromwich, and M. C. Serreze, 2000: The atmospheric hydrologic cycle over the Arctic basin from reanalyses. Part I: Comparison with observations and previous studies. J. Climate, 13, 923-937.

Dahl-Jensen, D., S. J. Johnson, C. U. Hammer, H. B. Clausen, and J. Jouzel, 1993: Past accumulation rates derived from observed annual layers in the GRIP ice core from Summit, central Greenland, 1993. Ice in the Climate System, W. R. Peltier, Ed., NATO ASI Series Vol. 12, Springer-Verlag, 517-532.

Deser, C., J. H. Walsh, and M. S. Timlin, 2000: Arctic sea ice variability in the context of recent atmospheric circulation trends. J. Climate, 13, 617-633.

Dethloff, K., A. Rinke, R. Lehmann, J. H. Christensen, M. Botzet, and B. Machenhauer, 1996: Regional climate model of the Arctic atmosphere. J. Geophys. Res., 101, 23 401-23 422.

Fischer, H., D. Wagenbach, and S. Kipfstuhl, 1998a: Sulfate and nitrate firn concentrations on the Greenland ice sheet. 1. Largescale geographical deposition changes. J. Geophys. Res., 103, 21 927-21934.

- M. Werner, D. Wagenbach, M. Schwager, T. Thorsteinnson, F. Wilhelms, and J. Kipfstuhl, 1998b: Little ice age clearly recorded in northern Greenland ice cores. Geophys. Res. Lett., 25, 17491752.

Fisher, D. A., R. M. Koerner, K. Kuivinen, H. B. Clausen, S. J. Johnsen, J.-P. Steffensen, N. Gundestrup, and C. B. Hammer, 1996: Inter-comparison of ice core delta $18 \mathrm{O}$ and precipitation records from sites in Canada and Greenland over the last 3500 years and over the last few centuries in detail using EOF technique. Climatic Variations and Forcing Mechanisms of the Last 2000 Years, P. D. Jones, Ed., NATO ASI Series, Vol. 41, Springer, 297-328.

Genthon, C., and A. Braun, 1995: ECMWF analyses and predictions of the surface climate of Greenland and Antarctica. J. Climate, 8, 2324-2332.

Gibson, J. K., P. Kalberg, S. Uppala, A. Hernandez, A. Nomura, and E. Serrano, 1997: ERA description. ECMWF Re-Analysis Project Report, Series 1, 72 pp.

Giorgi, F., and L. O. Mearns, 1999: Regional climate modeling revisited. J. Geophys. Res., 104, 6335-6352. 
Gorshkov, S. G., Ed.,1983: Arctic Ocean. Vol. 3, World Ocean Atlas, Pergamon Press, 189 pp.

Hansen, J., and Coauthors, 1997: Forcings and chaos in interannual to decadal climate change. J. Geophys. Res., 102, 25 679-25 720 .

Jung-Rothenhäusler, F., 1998: Fernerkundungs- und GIS-Studien in Nordostgrönland. Berichte zur Polarforschung, No. 280, AlfredWegener-Institut für Polar- und Meresforschung, Bremerhaven, Germany, $161 \mathrm{pp}$.

Källén, E., Ed.,1996: HIRLAM documentation manual, system 2.5. The Swedish Meteorological and Hydrological Institute. [Available from SMHI, S-60176 Norrköping, Sweden.]

Kapsner, W. R., R. B. Alley, C. A. Shuman, S. Anandakrishnan, and P. M. Grootes, 1995: Dominant influence of atmospheric circulation on snow accumulation in Greenland over the past 18,000 years. Nature, 375, 52-54.

Kattsov, V. M., J. E. Walsh, A. Rinke, and K. Dethloff, 2000: Atmospheric climate models: Simulations of the Arctic Ocean fresh water budget components. The Freshwater Budget of the Arctic Ocean, E. L. Lewis, Ed., Kluwer Academic, 209-247.

Lynch, A. H., G. B. Bonan, F. S. Chapin III, and W. Wu, 1999: The impact of tundra ecosystems on the surface energy budget and climate of Alaska. J. Geophys. Res., 104, 6647-6660.

Machenhauer, B., 1988: The HIRLAM final report. HIRLAM Tech. Rep. 5, DMI, Copenhagen, Denmark, 116 pp.

Ohmura, A., and N. Reeh, 1991: New precipitation and accumulation maps for Greenland. J. Glaciol., 37, 140-148.

__, P. Calanca, M. Wild, and M. Anklin, 1999: Precipitation, accumulation and mass balance of the Greenland ice sheet, $Z$. Gletscherkd. Glacialgeol., 35, 1-20.

Palmer, T. N., 1993: A nonlinear dynamical perspective on climate change. Weather, 48, 313-326.

Rinke, A., and K. Dethloff, 2000: On the sensitivity of a regional Arctic climate model to initial and boundary conditions. Climate Res., 14, 101-113.

_ - _ J. H. Christensen, M. Botzet, and B. Machenhauer, 1997: Simulation and validation of Arctic radiation and clouds in a regional climate model. J. Geophys. Res., 102, 29 833-29 847. - —, A. Spekat, W. Enke, and J. H. Christensen, 1999: High resolution climate simulations over the Arctic. Polar Res., 18, $143-150$.

— A. H. Lynch, and K. Dethloff, 2000: Intercomparison of Arctic regional climate simulations: Case studies of January and June 1990. J. Geophys. Res., 105, 29 669-29 683.

Roeckner, E., and Coauthors, 1996: The atmospheric general circulation model ECHAM-4: Model description and simulation of present-day climate. MPI Rep. 218, MPI, Hamburg, Germany, $90 \mathrm{pp}$.

Rogers, J. C., C. C. Wang, and M. J. McHugh, 1998: Persistent cold climatic episodes around Greenland and Baffin Island: Links to decadal-scale surface temperature anomalies. Geophys. Res. Lett., 25, 3971-3974.

Serreze, M. C., J. E. Box, R. G. Barry, and J. E. Walsh, 1993: Characteristics of Arctic synoptic activity, 1952-1989. Meteor. At mos. Phys., 51, 147-164.

__ J. A. Maslanik, J. R. Key, R. F. Kokaly, and D. A. Robinson, 1995: Diagnosis of the record minimum in Arctic sea-ice area during 1990 and associated snow cover. Geophys. Res. Lett., 22, 2183-2186.

_ , F. Carse, R. G. Barry, and J. C. Rogers, 1997: Icelandic low cyclone activity: Climatological features, linkages with the $\mathrm{NAO}$, and relationships with recent changes in the northern hemisphere circulation. J. Climate, 10, 453-464.

Sevruk, B., 1986: Correction of precipitation measurements: Swiss experience. Correction of Precipitation Measurements, B. Sevruk, Ed., Züricher Geographische Schriften, Vol. 23, ETH Zürich;187-196.

Smith, W., and P. Wessel, 1990: Gridding with continuous curvature splines intension. Geophysics, 55, 293-305.

Sommer, S., 1996: Hochauflösende Spurenstoffuntersuchungen an Eisbohrkernen aus Nord-Grönland. M.S. thesis, Physics Institute, University of Bern, Bern, Switzerland.

Sundqvist, H., 1988: Parameterization of condensation and associated clouds for weather prediction and general circulation simulations. Physically based Modeling and Simulation of Climate and Climate Change, M. E. Schlesinger, Ed., Reidel, 433-461.

Tiedtke, M., 1989: A comprehensive mass-flux scheme for cumulus parameterization in large-scale models. Mon. Wea. Rev., 117, $1779-1800$.

Wilhelms, F., 1996: Leitfähigkeits- und Dichtemessung an Eisbohrkernen. Berichte zur Polarforschung, No. 191, Alfred-WegenerInstitut für Polar- und Meresforschung, Bremerhaven, Germany, 224 pp.

_, J. Kipfstuhl, H. Miller, K. Heinloth, and J. Firestone, 1998: Precise dielectric profiling of ice cores: A new device with improved guarding and its theory. J. Glaciol., 44, 171-174. 